\title{
Biological versus Feminists Perspectives on Girls' Underperformance in STEM Subjects in Pakistan
}

\author{
Raza Ullah ${ }^{1-2}$, Hazir Ullah ${ }^{3}$ and Muhammad Bilal ${ }^{2-4 *}$ \\ 1. School of Education and Social Work, The University of Sydney, Australia. \\ 2. Department of Sociology, International Islamic University, Islamabad, Pakistan. \\ 3. Department of Sociology, Qauid-e-Azam University, Islamabad, Pakistan. \\ 4. Department of Sociology, Abdul Wali Khan University, Mardan, Pakistan.
}

Published Online: August 3, 2020

\begin{abstract}
This article outlines the biological essentialists' versus feminists' explanations of girls' underperformance in science, technology, engineering, and mathematics (STEM). Historically, except in the contexts of some developed countries, boys dominated girls in STEM subjects. Biological essentialists associate girls' underperformance in STEM with the innate differences between men and women, whereas feminists attribute it to social factors. The issue, however, is not so easily solved and there is an ongoing debate between biological essentialists and feminists. This article, thus, engages in a comparative analysis of the two approaches, their underlying principles and the empirical evidences they use to substantiate their stance. The analysis of both approaches enables the authors to better decipher the connection between gender and education performance. This article explains that social rather than biological factors influence girls' performance in STEM subjects. The article concludes that girls' underperformance in STEM subjects' results from sociocultural factors.
\end{abstract}

Keywords: Biological Essentialists, Feminists, Underperformance in Education, STEM.

\section{Introduction}

It is now an established fact that girls are outperforming boys in a wide range of academic subjects (Ullah \& Ullah, 2019). Nevertheless, they are underperforming in science, technology, engineering and math (STEM). This article outlines the biological essentialist versus feminists' explanations of the causes of gender difference in STEM. Traditionally, STEM remain heavily male dominated and masculine fields ( Hedges \& Nowell, 1995; Ullah \& Ullah, 2019). Boys are surpassing girls in the subjects of science (Perez-Felkner et al., 2017; Williams et al., 2009). For instance, Sinnes (2006) argued that boys outperform girls in STEM subjects. Based on Sinnes's study findings, it is asserted that this trend has been increasing over time, particularly in developing word. The under-performance of girls in the subjects of science is a world-wide phenomenon (Burke \& Mattis, 2007; Ceci \& Williams, 2011; Ullah et al., 2019). However, in developed countries such as united states of America, Canada, United Kingdom and Australia, girls outshine boys in the subjects of science (Thomas \& Smith, 2004). In these developed countries, there are no significant differences in masculinity and femininity; therefore, girls compete boys in all fields including science education. For example, the findings of the study conducted by Ullah and Ullah (2019) revealed that girls and boys do well in science subjects. 
They argued that girls' and boys' performance is similar in science in developed countries. Machin and McNally (2005) asserted that the gap in science was once very wide in the favor of male students, has now been narrowed. With the exception of few developed countries, girls still fall behind in science subjects (Asante, 2010). Asante further reveals that overall boys score higher grades than girls in science subjects. The pointed to be noted here is that why in some countries girls compete boys in science subjects and in some countries fail to outperform in science (Ullah \& Ullah, 2019).

This article critically analyses girls' underperformance in STEM. It examines two main approaches towards gender and education a) biological and b) feminist perspective. Biological perspective links girls' underperformance in STEM with sex differences and believes in the brain differences between boys and girls. Feminist perspective, with an insight from social constructionism, considers sociocultural factors responsible for girls' performance and interest in science subjects. The first part of this paper discusses biological theories and the discourses they use to link girls' underperformance and lack of interest in science with their biology. The second part of the paper outlines girls' underperformance in science subjects from feminists' point of views. Before we discuss biological and feminist perspectives on gender and STEM education, it is important to briefly introduce the concept of gender and STEM education.

\subsection{Sex or Gender}

Should we use the term sex or gender? This debate is not so easily solved and is still subject of an ongoing debate between essentialists and social constructionists. (Ullah, 2018). The terms gender and sex are interchangeably used (Reeder, 1996). However, sociologists distinguish gender from sex. Sex simply refers to biological classification: this has traditionally been men and women and also includes intersex and 'trans' (Mccormack, 2018). Sex, thus, is biological and tends to remain stable over time and space. In simple word, sex refers to male and female or it means biological differences between women and men which are mostly permanent and universal whereas "gender refers to masculinity and femininity or socially constructed roles of men and women.... This means that we inherit our sex and learn our gender" (Ullah, 2013: 07). Drawing on the differences, it is argued that gender is acquired through interaction and it is subjected to changes. Similarly, the meaning and construction of gender depend on culture. Thus, gender is quite different concept than sex.

Sex is innate and refers to biological and physiological differences between male and female. Gender is learned and encompasses a set of differences between male and female. Similarly, gender refers to the personal traits and social position that members of society attach to being female or male. According to Gould (1977), gender is socially accepted femininity or masculinity. Oakley (2016) argues that gender is the social classification of human into masculine and feminine beings. Gender is a classifying principle in society and culture. It is a remarkable discriminating tool in the distribution of labour, care, possession, income, education, organizational qualities or diseases.

\subsection{STEM Education}

STEM is commonly referred to fields or academic domains considered hard sciences or natural sciences (Gonzalez \& Kuenzi, 2012). The term STEM encompasses science, technology, engineering, and math subjects. It is noteworthy to mention here that STEM subjects vary by 
educational levels (Breiner et al., 2012). For instance, at primary level, STEM subjects are an alternative word for math and science curriculum. STEM, however, covers physics, chemistry, technology as the level changes from primary to secondary and higher secondary levels. In sociology of education, STEM is used to refer to a set of subjects taught at secondary and higher secondary school levels such as science, technology, engineering, math and chemistry (Xie et al., 2015). In order to establish our argument, we use the term STEM for subjects which are taught at secondary and higher secondary levels. These popularly include math, physics, chemistry and engineering.

\subsection{Materials and Methods}

This review paper critically and comparatively engages biological determinists' and social constructionists' explanations and arguments around the issue of gender differences in STEM subjects. The article utilized theoretical review and findings from empirical studies for substantiating the claim that girls' underperformance in STEM subjects is not due to their biology but is caused by sociocultural forces. The paper critically examined the two main approaches (biological essentialists versus social constructionists) approaches towards gender and education. A concise and comparative analysis of both approaches is essential and insightful because notions of 'gender' and 'education performance' are understood and explained in strikingly different ways. It is claimed that this may be very helpful for readers who intend to carry out research in the area of gender differences in educational performance in general and STEM education in particular. This study reaches to a set of conclusions that are supported by empirical evidences which add meaning to the existing debate.

\section{Discussion and Findings}

This article is concerned with theoretical debate and empirical studies of girls' underperformance in STEM. This main section highlights how both biological essentialists and social constructionists explain the gender differential performance in STEM.

\subsection{Girls' Underperformance in STEM Subjects and Biological Theories}

The first tempt to explain differences between male and female were biological theories. The advocates of biological theories claim that the sex differences between male and female are the basis of gender differences in educational performance (Roberts, 2000). These innate sex differences can be found in three areas: intelligence level, reasoning skills and prenatal hormones. We will discuss the first two i.e. intelligence and cognitive differences as they are commonly used in sociology of education and gender issues (Sarseke, 2018). It is important to highlight here that boys and girls intelligence level mainly depend on brain theory. The size of brain and its connection with human intellect could explain some behavioural and intellectual differences between boys and girls (Wilson et al., 2012). Scientists have explored the brain structure of boys and girls and noted that boys and girls have different brain size. Lai, (2010) found that there is difference in the structure of the brain of both sexes. Lai noted that the brain of male is a type $\mathrm{S}$, which means systematizing and therefore people with brain type $\mathrm{S}$, are interested in reasoning and tend to play with mechanical toys and the brain of woman is type E which means, empathizing, and people with type E brain intent to play with dolls. We deem it important to mention it here that the followers of brain theory make it a base of girls' underperformance in STEM subjects. One of the followers of brain theory is Dr. Edward Clarke. Clarke asserted that women brain are not that much advanced to do well in higher 
education like men (Seller, 1983). Similarly, the other set of biological theories has associated gender gap in STEM education with differences in cognitive abilities and skills. Researchers observed that boys' performance in STEM education is good while girls do well in verbal abilities that's why they perform well in arts and humanities and fail in subjects that involve reasoning abilities (Hedges \& Nowell, 1995). Wang and Degol (2017) asserted that females are better in verbal and theoretical learning and therefore they do not select STEM subjects because they lack mathematical reasoning. Girls lack better cognitive skills which are important in STEM subjects and that's why they fall behind in STEM education (Ceci \& Williams, 2011).

Another controversial theory of biological differences between men and women is sociobiology theory. This theory states that genetic factors cause differences between male and female. Similarly, another focus of biological theories is physiological differences between male and female. Followers of physiological differences believe that biological differences differently affect the behaviour of men and women. Men are physically stronger than women which enables them (men) to see the world in a better way than women in terms of ideas and reasoning. Geiger et al., (2015) argued that women are sluggish, passive and uninterested in politics because of their biology. On the other hand, men are energetic, eager and interested in politics because of their biology. Another main argument of biological theories is that sex differences and biology affect learning and working ability. Girls' menstruation and physique intervene with their studies. In line with this, Clark related reasoning and learning abilities of women with their menstruation. Hubbard in his book "The politics of women's biology" citing Clark Blickenstaff, (2005) writes:

"There have been instances, and I have seen such, of females, in whom the special mechanism we are speaking of remained germinal,-undeveloped. It seemed to have been aborted. They graduated from school or college excellent scholars, but with undeveloped ovaries. Later they married, and were sterile" (Hubbard, 1990, p.39)

We quoted Clark at such length because today, we see evidences that show girls outstanding performance in education (Brown \& Gilligan, 1993). This makes Clark work less important in contemporary scholarship. It is important to discuss his work here as his work did not go unchallenged for decades. For example, Thomas Wentworth Higginson pointed out that girls underachievement previously linked with the lack of opportunities and gendered and prejudiced culture (Hubbard, 1990). He further asserted that today girls have access and opportunities of getting education, so they are outperforming boys even after puberty. Thus menstruation does not affect their learning ability. Girls are dominating boys even in traditionally masculine subjects in industrialized countries. This gives a strong ground and base to argue that academic performance is rooted in socio-cultural forces instead of biology.

\subsection{Girls' Underperformance in STEM subjects; Social Constructionists and Feminist Explanations}

In the nature versus nurture debate, sociologists dominantly put on the shoes of nurture and believe that masculinity and femininity are the products of nurture. They believe that females become women through the process of socialization whereby they learn feminine traits and behaviours and males become men and learn masculine traits (Ullah, 2013). In the same fashion they believe that girls' underperformance in SETM is not due to girls' biology but is due to social environment and opportunities available to them. 
Feminists have challenged theories of brain and innate differences as the core reasons of gender inequality in academic performance. To have a detailed discussion on gender differences in academic performance from the perspective of feminist scholars, we deem it important to briefly explain feminism, branches of feminism and waves of feminism. Feminism is the advocacy of social equality for men and women, in opposition to patriarchy and sexism (Macionis, 2009). Feminism drew attention to the women inferior place in society. The first wave of feminism started in the United States in the 1840s and worked to achieve gender equality in society. Similarly, radical feminist researchers embraced differences in education between male and female due to patriarchal structure. The radical feminists noticeably argue that patriarchy is not only prevailing in family but it has been extended to all other institutions. All feminists are united on a single point-patriarchy and male dominance as the key reasons of women subordinate position in society. Biological theories associated girls' failure in all fields, including education, with sex difference and differences. Feminists strongly disagree and state that the differences between masculinity and femininity are due to male dominated and biased culture and norms. Boys and girls are treated differently. The differential and discriminatory treatment extend to every field.

According to Francis (2002), majority of the societies are patriarchal and this is the core reasons of differences between masculinity and femininity. These differences, according to her, make women inferior in society. Moreover, gender is largely influenced by a range of factors including class, culture, ability, and religion. It is important to mention here that gender is not fixed but influenced by different discourses. Thus, Francis, asserts that gender is socially constructed by different gender discourses. Men are positioned and repositioned in public sphere in powerful discourses while female are only positioned in the domestic spheres (Francis, 2002). As Millett in Sexual Politics argues that the omnipresent nature of patriarchy and the ways it drew attention to the pervasiveness of patriarchy and to the ways in which it is supported through family and culture are the roots causes of gender inequality in society including education (Millett, 2016). Thus, Millet very emphatically argues that gender inequality in education is not merely tied with sex differences rather this is rooted in the patriarchal culture. This means that girls and boys performance in education need to be understood in terms of the surrounding and culture they have. In the light of the above discussion, it can be argued that girls underperformance in the past was mainly tied with biological differences. It was the feminists' struggle that girls in gender neutral society began to perform well, challenged the discourse that support biological differences. This means that girls' deprivation in society is highly influenced and impacted by patriarchal culture and traditional practices of socialization. Feminists voiced for equal and gender free society where both boys and girls get training and grow in equal environment (Millett, 2016). They were believing that sex differences were over emphasized and social and cultural influences have been undermined.

Building on the work of Francs Millet, we assert that girls and boy are equal by birth and there is no innate differences that cause girls poor performance and lack of interest in education. Boys and girls, after their birth, get and develop different image of society and this rather than sex and innate differences influence them throughout their life, in terms of their choice and interest. Having said this, we convincingly argue that the basic assumption of the feminist work is that the differences between male and female are more prevalent and influential in making difference in academic performance of boys and girls. The gendered academic performance and girls underachieving in STEM education are the direct response of these gendered and traditional practices of socialization. In developed societies, where gender is no longer 
important, girls outshine boys even in STEM subjects (Clark Blickenstaff, 2005). This means that differences between masculinity and femininity set different choices and interest for boys and girls.

Blake et al., (2011) argue that girls in traditional and rural societies are underachieving in education because education in such societies are not at the likelihood of femininity. This masculine and feminine traits which is constructed and developed through traditional practices of socialization, become the core reasons of girls' underperformance in education. Based on this, we argue that, in urban areas, the traditional practices of socialization are weakening. Girls unlike rural and traditional societies are now getting opportunities of approaching public domains, which has changed their role in society. In field of education, due to this transition, girls are now outstripping boys in academic performance. In developing society, STEM is considered masculine fields which badly influence girls' interest as well as performance in STEM education. The argument is thus based on the assumption that girls underperformance in education in past was the outcome of girls inferior and subordinate position in society. As argued by another renowned advocate of feminism, Wollstonecraft in her book "A Vindication of the Rights of Women" published in 1972 asserts that woman has been defined as inferior by man and is not based on reality because her inferior position is largely influenced by societal norms and values. Thus, culture, norms and values are making women inferior and prevent them from entering to public domain including education, although they have similar level of reasoning. Based on the argument of Wollstonecraft, we assert that culture and societal norms stereotypically considered girls fit for domestic and inferior roles. Education in general and STEM education in particular, are considered public domain and male hegemony, which discourage girls' interest in STEM fields. Boys and girls differences in academic performance in STEM are not innate and biological but the outcome of cultural and societal definition of masculinity and femininity.

This means that no one is born genius or less genius. It is society and culture which make the differences. Nancy Cott in her 'difference' and 'sameness' debates, asserts that women have the same intellectual qualities as men but due to cultural constrains and patriarchal structure, women do not get equal access to public spheres including education (Cott, 1987). Drawing on Cott, we argue that girls' poor performance in education was the direct response of cultural barriers and male dominancy over public domains. Thus, to conclude Nancy Cott work, it is stated that its society and culture that make girls inappropriate and suitable for public domain including education. This shows that girls when born are treated and grown with a different image of society. It means that femininity and masculinity are constructed and developed in gender imbalance society, favoring boys that make boys more suitable for education. Simone de Beauvoir, who is a French feminist and supports the similar views, Simone de Beauvoir' work (as cited in Hossain, 2017) revealed in the following way.

"One is not born, but rather becomes a woman. No biological, psychological, or economic fate determines the figure that the human female presents in society; it is civilization as a whole that produces this creature, intermediate between and eunuch, which is described as feminine" (Hossain Simone, 2017, p.89).

The above quote indicates that how girls are influenced and associated with inferior roles and position in society. Women are made rather than being born and societal norms and values are decisive in this construction. In line with this, she further argued that women are "other" in society. Culture and civilization has placed women in inferior position while regarded men 
superior and considered them normal. We would argue here that boys in society is seen as the default, natural, and dominant one; whereas girl is the 'other', passive and subordinate, with no distinct role of her own in life other than that of supporting man and his ambitions. These differences influence girls for entire life. Drawing on this, it is asserted that such difference are more prevalent in developing societies and this the fact that girls in such societies are lagging behind in education particularly in STEM education. This passive and subordinate position of girls in society are considered unfit in the field of education, especially in Science, technology, engineering and mathematics. In conclusion, it can be argued that feminist scholars very persuasively assert that gender is highly influenced by male perspectives. They strictly oppose and challenge sex and innate differences for girls' underperformance in education, particularly in STEM education. They stated that biological and essentialist views were over emphasized in early 1970s and 80s. As argued by Francis (2002) that girls were underperforming in education in 1970s and 80s, as there were huge differences between masculinity and femininity but these were not critically and realistically analysed.

\section{Conclusion}

In this article we outlined the biological essentialists' and feminists' explanations on girls' underperformance in STEM education. The explanations and arguments of both groups are based on different epistemological stances about gender and education performance. Giving a succinct and comparative account of the differences between the two approaches, it can be argued that feminists' stance is more convincing. It is academically convincing to believe that girls' -underperformance in STEM is caused by gendered socialization and male dominated social and cultural practices. We position ourselves with feminists' standpoint and substantiate our assertion-girls' underperformance in STEM is due to social not biological factors-with the global gender reverse change in educational performance-girls' outperformance and boys' underperformance in most of the academic fields (Ullah \& Ullah, 2019). Girls, across societies, outperform boys. This gender reverse change in educational performance, except in STEM subjects, enables feminists to challenge the biological explanation of girls' underperformance in STEM. It gives them strong ground to argue that socio-cultural factors are responsible for girls' underperformance in STEM (Mucee et al., 2014; Ullah et al., 2019; Ullah \& Ullah, 2019). Many studies in the global north have revealed that girls are outperforming boys even in the traditionally masculine subjects in countries where gender is no longer important (Kindlon, 2007; Ullah \& Ullah, 2019). The nub of discussion here is that girls can do well in STEM subjects if they are given conducive, secure and friendly environment.

\section{References}

Acker, S. (1987). Feminist theory and the study of gender and education. International Review of Education, 33(4), 419-435.

Asante, K. O. (2010). Sex differences in mathematics performance among senior high students in Ghana. Gender and Behaviour, 8(2), 3279-3289.

Baker, D. P., \& Jones, D. P. (1993). Creating gender equality: Cross-national gender stratification and mathematical performance. Sociology of Education, 91-103.

Blake, J. J., Butler, B. R., Lewis, C. W., \& Darensbourg, A. (2011). Unmasking the inequitable discipline experiences of urban Black girls: Implications for urban educational stakeholders. The Urban Review, 43(1), 90-106.

Breiner, J. M., Harkness, S. S., Johnson, C. C., \& Koehler, C. M. (2012). What is STEM? A 
discussion about conceptions of STEM in education and partnerships. School Science and Mathematics, 112(1), 3-11.

Brown, L. M., \& Gilligan, C. (1993). Meeting at the crossroads: Women's psychology and girls' development. Feminism \& Psychology, 3(1), 11-35.

Burke, R. J., \& Mattis, M. C. (2007). Women and minorities in science, technology, engineering, and mathematics: Upping the numbers. Edward Elgar Publishing.

Ceci, S. J., \& Williams, W. M. (2011). Understanding current causes of women's underrepresentation in science. Proceedings of the National Academy of Sciences, 108(8), 3157-3162.

Clark Blickenstaff, J. (2005). Women and science careers: Leaky pipeline or gender filter? Gender and Education, 17(4), 369-386.

Cott, N. F. (1987). The grounding of modern feminism. Yale University Press.

Francis, B. (2002). Boys, girls and achievement: Addressing the classroom issues. Routledge.

Geiger, R. L., Rothblatt, S., Woodward, K., Moses, Y., Kleinman, D. L., Melin, C., Nowviskie, B., McGowan, J., Williams, J. J., \& Newfield, C. (2015). A New Deal for the Humanities: Liberal Arts and the Future of Public Higher Education. Rutgers University Press.

Gonzalez, H. B., \& Kuenzi, J. J. (2012). Science, technology, engineering, and mathematics (STEM) education: A primer.

Gould, M. (1977). Toward a sociological theory of gender and sex. The American Sociologist, 182-189.

Hedges, L. V., \& Nowell, A. (1995). Sex differences in mental test scores, variability, and numbers of high-scoring individuals. Science, 269(5220), 41-45.

Hossain, T. (2017). "One is Not Born, But Rather Becomes, A Woman": Becoming Woman in Tahmima Anam's Works [PhD Thesis]. East West University.

Hubbard, R. (1990). The politics of women's biology. Rutgers University Press.

Kindlon, D. (2007). Alpha girls: Understanding the new American girl and how she is changing the world. Rodale Books.

Lai, F. (2010). Are boys left behind? The evolution of the gender achievement gap in Beijing's middle schools. Economics of Education Review, 29(3), 383-399.

Machin, S., \& McNally, S. (2005). Gender and student achievement in English schools. Oxford Review of Economic Policy, 21(3), 357-372.

Macionis, J. J. (2009). Society: The basics. Pearson/Prentice Hall.

Millett, K. (2016). Sexual politics. Columbia University Press.

Mucee, J. N., Rechee, J., Bururia, D., \& Gikunda, R. M. (2014). Socio-cultural factors that influence access to secondary school education in Tharaka South Sub-County, Kenya. International Journal of Education and Research, 2(10), 489-502.

Oakley, A. (2016). Sex, gender and society. Routledge.

Perez-Felkner, L., Nix, S., \& Thomas, K. (2017). Gendered pathways: How mathematics ability beliefs shape secondary and postsecondary course and degree field choices. Frontiers in Psychology, 8, 386.

Reeder, H. M. (1996). A critical look at gender difference in communication research. Communication Studies, 47(4), 318-330.

Roberts, C. (2000). Biological behaviour? Hormones, psychology, and sex. NWSA Journal, 120.

Sarseke, G. (2018). Under-Representation of women in science: From educational, feminist and scientific views. NASPA Journal About Women in Higher Education, 11(1), 89101. 
Seller, M. S. (1983). Dr. Clarke vs. the" Ladies": Coeducation and Women's Roles in the 1870 's.

Sinnes, A. (2006). Approaches to gender equity in science education: Three alternatives and two examples. African Journal of Research in Mathematics, Science and Technology Education, 10(1), 1-12.

Thomas, S. P., \& Smith, H. (2004). School connectedness, anger behaviours, and relationships of violent and nonviolent American youth. Perspectives in Psychiatric Care, 40(4), $135-148$.

Ullah, Hazir (2018). Ideologies \& Power in the Textbooks: Reproduction of Gender and Class Hierarchies. Islamabad: IRD Press

Ullah, H. (2013). Reproduction of Class and Gender Hierarchies through Education in Khyber Pakhtunkhwa (PhD Thesis). University of Peshawar, Pakistan.

Ullah, R., \& Ullah, H. (n.d.). Boys versus girls' educational performance: Empirical evidences from global north and global south.

Ullah, R., \& Ullah, H. (2019). Boys versus Girls' Educational Performance: Empirical Evidences from Global North and Global South. African Educational Research Journal, 7(4), 163-167.

Ullah, R., Ullah, H., \& Allender, T. (2019). Girls Underperforming in Science: Evidences from Khyber Pakhtunkhwa, Pakistan. Journal of Elementary Education, 29(2), 1-14.

Ullah, R., Ullah, H., Sevari, K., Rezaei, M., Ndegwa, A., Gutiérrez-Colón, M., Chirume, S., Thondhlana, S., \& Kasap, S. (2019). Boys versus girls' educational performance: Empirical evidences from global north and global south. African Educational Research Journal, 7(10), 20-25.

Wang, M. T., \& Degol, J. L. (2017). Gender gap in science, technology, engineering, and mathematics (STEM): Current knowledge, implications for practice, policy, and future directions. Educational Psychology Review, 29(1), 119-140.

Williams, J., Greene, S., Doyle, E., Harris, E., Layte, R., McCoy, S., McCrory, C., Murray, A., Nixon, E., \& O'Dowd, T. (2009). Growing up in Ireland national longitudinal study of children. The lives of 9 year olds.

Wilson, N. J., Shuttleworth, R., Stancliffe, R., \& Parmenter, T. (2012). Masculinity theory in applied research with men and boys with intellectual disability. Intellectual and Developmental Disabilities, 50(3), 261-272.

Xie, Y., Fang, M., \& Shauman, K. (2015). STEM education. Annual Review of Sociology, 41, 331-357. 